\title{
THE 8.4 MW MODULATOR/REGULATOR POWER SYSTEMS FOR THE ELECTRON CYCLOTRON HEATING FACILITY UPGRADE AT DIII-D
}

\author{
by \\ S.G.E. PRONKO and D.S. BAGGEST
}

This is a preprint of a paper to be presented at the 18th IEEE/NPSS Symposium on Fusion Engineering, October 25-29, 1999, in Albuquerque, New Mexico, and to be published in the Proceedings.

\author{
Work supported by \\ the U.S. Department of Energy \\ under Contract No. DE-AC03-99ER54463
}




\section{DISCLAIMER}

This report was prepared as an account of work sponsored by an agency of the United States Government. Neither the United States Government nor any agency thereof, nor any of their employees, make any warranty, express or implied, or assumes any legal liability or responsibility for the accuracy, completeness, or usefulness of any information, apparatus, product, or process disclosed, or represents that its use would not infringe privately owned rights. Reference herein to any specific commercial product, process, or service by trade name, trademark, manufacturer, or otherwise does not necessarily constitute or imply its endorsement, recommendation, or favoring by the United States Government or any agency thereof. The views and opinions of authors expressed herein do not necessarily state or reflect those of the United States Government or any agency thereof. 


\section{DISCLAIMER}

\section{Portions of this document may be illegible in electronic image products. Images are produced from the best available original document.}




\title{
The 8.4 MW Modulator/Regulator Power Systems for the Electron Cyclotron Heating Facility Upgrade at DIII-D
}

\author{
S.G.E. Pronko and D.S. Baggest \\ General Atomics, DIII-D National Fusion Facility, P.O. Box 85608, San Diego, California 92186-5608
}

\begin{abstract}
Over the next three years the DIII-D National Fusion Facility at General Atomics will upgrade its electron cyclotron heating (ECH) capability from the present $3 \mathrm{MW}$ at $110 \mathrm{GHz}$ to $10 \mathrm{MW}$ of injected microwave power. There will be ten gyrotron tubes supplied by five $8.4 \mathrm{MW}$ modulator/regulator (M/R) power systems. The project has gained considerable leverage from the acquisition of surplus hardware from the MFTF program that was conducted at LLNL in the early 1980 s. One of these systems had been refurbished and converted for use as an ECH power supply earlier. The experience gained and the lessons learned from operating that system have proved valuable in guiding the engineering of the new systems. This paper provides an overview of the power system design and a report on the present status of the project.
\end{abstract}

\section{INTRODUCTION AND SYSTEM OVERVIEW}

The upgrade of the DIII-D electron cyclotron heating (ECH) capability from $3 \mathrm{MW}$ to $6 \mathrm{MW}$ [1] (and later to $10 \mathrm{MW}$ ) of injected microwave power would require the addition of five new power systems to supply ten gyrotrons. The availability of surplus hardware from Lawrence Livermore National Laboratory (LLNL), developed for the Mirror Fusion Test Facility (MFTF), provided a basis for the new power system design. The power systems from MFTF were originally designed for neutral beam injectors and contained hardware that would not be required for gyrotron service. In addition to the elimination of the superfluous components, some design changes would be necessary in order to meet the DIII-D ECH performance requirements. In 1989, one of these surplus power systems was converted for use as a gyrotron power system at DIID. From that operational experience, the following key points were learned: 1) the rectifier transformer had limited ability to mechanically withstand repeated crowbar events; 2) the voltage ratings of the crowbar switch and the filter capacitor bank were marginal, leading to unpredictable selfbreakdown of the ignitron switches and partial discharges within the capacitors; 3 ) the bandwidth and stability of the grid driver amplifier and the feedback loop were insufficient to meet the desired regulation and modulation goals; 4) the control system contained obsolete and unsupportable hardware and was complicated with neutral beam injector specific requirements.

The planned use of each new power system is the operation of two diode gun gyrotrons in parallel. The terminal requirements of the gyrotrons are:

$\begin{array}{ll}\text { Cathode voltage: } & (-) 70-86 \mathrm{kV} \\ \text { Cathode current (per gyrotron): } & 35-40 \mathrm{~A} \\ \text { Pulse length (max): } & 10 \mathrm{~s} \\ \text { Cathode voltage dc regulation: } & <0.5 \% \\ \text { Cathode voltage modulation: } & 15 \% \text { at } 20 \mathrm{kHz} \\ \text { Response to load fault: } & <<10 \mu \mathrm{s}\end{array}$

Figure 1 is a simplified schematic diagram of the overall power system. The essential design is classic. Following the flow of power, the $12.47 \mathrm{kV} 60 \mathrm{~Hz} 3 \phi$ mains are connected through current-limiting line reactors to the protective switchgear. The switchgear consists of a line contactor, current-limiting fuses, and a fast interrupting circuit breaker. Following the switchgear is the ac/dc power supply which converts the $60 \mathrm{~Hz} 3 \phi$ power into dc voltage. Coarse adjustment of the power supply is accomplished by tap-changing in the step-regulator. The negative high voltage dc output of the power supply is transmitted through approximately $600 \mathrm{ft}$ of coaxial cable (Kerite EPR, $120 \mathrm{kVdc}$ ) to the input section of the modulator/regulator (M/R) vault. The $M / R$ vault is located within the facility building in close proximity to the gyrotrons. Within the M/R vault the power flows through an input $L / R$ network, through the $M / R$ tetrode, then through an output $L / R$ network and out to the gyrotron loads. Shunting the input of the $M / R$ is the protective crowbar switch and the filter capacitor bank.

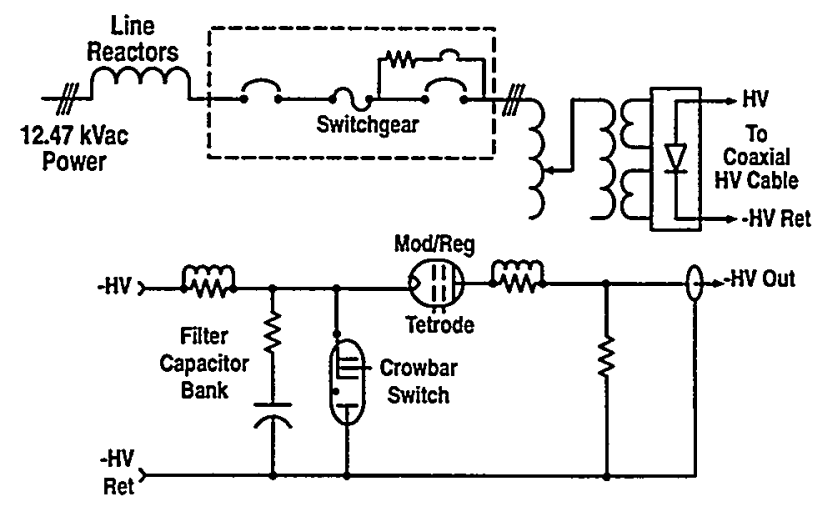

Fig. 1. A single-line illustration of the ECH power system.

\section{THE AC/DC POWER SUPPLY}

The conversion of the $60 \mathrm{~Hz}$ ac utility power to the unregulated high dc voltage is accomplished with the ac/dc power supply (ACDCPS). The ACDCPS is a classic, series connected delta-wye 12-pulse, full-wave rectified power supply. The specifications of the ACDCPS are: 
Primary voltage:

Step regulator range:

Rectifier transformer power:

Rectified dc output (max):

dc output power $(\max )$ :

Source impedance:
$12.47 \mathrm{kVac}, 3 \phi$

$6.8 \mathrm{kV}-13.1 \mathrm{kVac}$

9.2 MVA (pulse)

$-105 \mathrm{kV}, 80 \mathrm{~A}$

8.4 MW (30 s)

$133 \mathrm{mH}, 137 \Omega$
For the most part, the original MFTF ACDCPS was installed "as received" with the exception of the addition of the current-limiting line reactors and modifications to the rectifier transformer.

In the ten years of operation of the first MFTF power system at DII-D, it was found that the rectifier transformer could not withstand the impulsive forces from repeated crowbarring of the power supply. Shims that separate and support the individual coil windings were shaken out of place allowing the coils to slip out of position and to unwind. A mechanical restraint was devised consisting of a system of phenolic caps and a fiber-reinforced banding ribbon. The U-shaped phenolic caps fit over each group of shims and are anchored in place by a nylon rivet. The banding ribbon was wound over the caps compressing them radially inward. By restraining the shims in this manner, the effect of the deflections due to crowbar impulses should be mitigated.

\section{THE CROWBAR SWITCH AND THE FILTER CAPACITOR BANK}

The main protective element in the power system is the energy divertor, or crowbar switch. In the event of a load fault, the crowbar switch is fired which effectively shunts the input terminals to the M/R. Energy that is stored in the filter capacitor bank and energy that continues to be delivered by the ACDCPS is diverted back to the source. This action limits the amount of energy absorbed by the fault, typically an arc of the gyrotron cathode. To be effective, a crowbar switch must 1) have a high speed response, 2) reliably fire when commanded, 3) indefinitely hold-off high voltage without spurious self-breakdown or triggering, 4) reliably conduct with a low starting voltage, and 5) transfer large amounts of electron charge. Criteria 1-3 provided much of the motivation for deciding to design a completely new crowbar switch system as opposed to using the original MFTF hardware. In addition, it was desired to eliminate the mercury filled ignitron switches from the system design. The new crowbar switch system would meet the following requirements:

$\begin{array}{ll}\text { Operating voltage: } & -105 \mathrm{kVdc} \\ \text { Peak current }(750 \mu \mathrm{s} \text { e-fold): } & 2 \mathrm{kA} \\ \text { Follow-on current: } & <1 \mathrm{kA}(25 \mathrm{~ms}) \\ \text { Charge transfer per shot: } & <20 \mathrm{Cb} \\ \text { Turn-on time and jitter: } & <1 \mu \mathrm{s} / 10 \mathrm{~ns}\end{array}$

The switch that was chosen for the new design is a low pressure deuterium filled device manufactured by English
Electric Valve (EEV). The HX-2500 has combined characteristics similar to a hydrogen thyratron and a triggered vacuum gap. The thyratron-like triggerability and high speed response combined with high charge transfer capability and a wide operating voltage range make the $\mathrm{HX}-2500$ an appropriate choice for crowbar service. At an operating voltage of $30 \mathrm{kVdc}$, the $\mathrm{HX}-2500$ exhibits a very low probability of self-breakdown [2]. To meet the DIII-D ECH requirement of $-105 \mathrm{kVdc}$, the crowbar switch system was designed to have four series stages, thus providing ample voltage hold-off margin. Construction of a single stage has been completed and results from preliminary testing are shown in Fig. 2. The delay between the grid drive pulse and the discharge current pulse is $<500 \mathrm{~ns}$. It is important to note that these tests were conducted with low anode voltage $(100-500 \mathrm{Vdc})$ which will be the typical condition when the crowbar is commanded to fire. The single stage was also high-potential tested to $30 \mathrm{kVdc}$ for 30 minutes. There were no incidences of self-breakdown and the leakage current was measured to be $<10 \mu \mathrm{A}$.

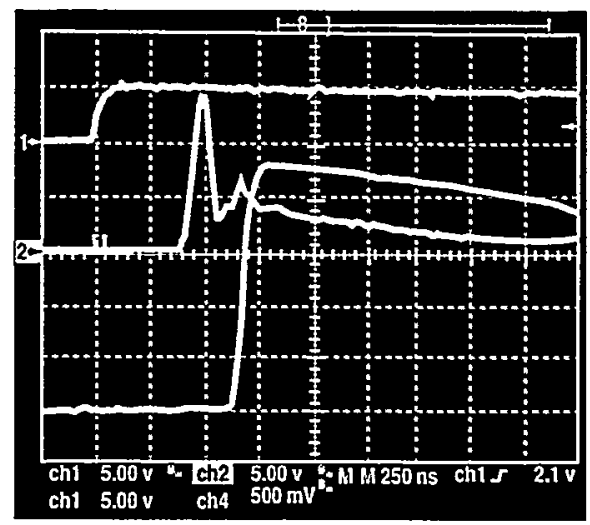

Fig. 2. Triggering tests of a single stage of the crowbar switch system. The top trace is the input fire command; the middle trace is the trigger grid voltage $(500 \mathrm{~V} / \mathrm{div})$; the bottom trace is the discharge current through the $\mathrm{HX}-2500(100 \mathrm{~A} / \mathrm{div})$. The horizontal scale is $250 \mathrm{~ns} / \mathrm{div}$.

The filter capacitor bank is used to smooth out the rectified power supply ripple and to provide passive transient compensation. The original MFTF hardware was composed of six series stages constructed with capacitors that are no longer manufactured. More importantly, however, the capacitor voltage rating was only $17.5 \mathrm{kVdc}$ leaving zero margin at the required operating level of $-105 \mathrm{kVdc}$. It was also desirable to reduce the amount of stored energy as well as the physical size of the capacitor bank. The original filter circuit parameters were $24 \mu \mathrm{F}$ and $150 \Omega$ storing a maximum energy of $132.3 \mathrm{~kJ}$. The selection of the new capacitor and the filter damping resistance values would involve trade-offs between available components, stored energy, ripple reduction, and circuit dynamics (damping and transient compensation). Through a combination of circuit analysis and working with capacitor manufacturers, a capacitance value of $5 \mu \mathrm{F}$ was chosen. The unit capacitor, manufactured by Maxwell Technologies, is rated at $20 \mu \mathrm{F}$ and 
$35 \mathrm{kVdc}$ so that a series connection of four stages results in an overall voltage rating of $140 \mathrm{kVdc}$. This provides for copious margin at the operating voltage level. The maximum stored energy under normal operating conditions is only $27.5 \mathrm{~kJ}$.

The filter elements and the ACDCPS source impedance $(133 \mathrm{mH}, 137 \Omega$ ) largely define the circuit dynamics. For a critically damped system the filter damping resistor would be chosen to have a value of $190 \Omega$. However, this leads to an unacceptable amount of $720 \mathrm{~Hz}$ power supply ripple at the input to the M/R. At $100 \Omega$ the ripple is acceptable but the circuit is underdamped. The underdamped natural response is not a problem in this case since the M/R tetrode will always be ramped to full load no faster than $1 \mathrm{~ms}$ (a requirement of the gyrotron). Even during a fast cut-off of the tetrode at full load, the transient voltage on the filter overshoots only $5 \%$ of the nominal level and settles within one cycle $(<2 \mathrm{~ms})$. In anticipation of future performance requirements, the provision for doubling the filter capacitance was designed into the capacitor bank structure. At a capacity of $10 \mu \mathrm{F}$, the system becomes critically damped.

\section{THE MODULATOR/REGULATOR}

The principal control element of the power system is the $M / R$. At the core of the $M / R$ is the high power tetrode (BBC CQK 200-4) vacuum tube. The tetrode is seated in a socket that is mounted to the M/R hot deck. The hot deck structure houses the grid driver amplifier, the screen grid subsystem, and the hot deck control interface. The structure is connected to the cathode potential of the tetrode and acts as a Faraday cage for the components it encloses. Two isolation transformers provide power for the tetrode filament $(21 \mathrm{~V}, 450 \mathrm{~A})$ and power for the $M / R$ subsystems $(480 \mathrm{~V}, 12 \mathrm{kVA}, 3 \phi)$.

Two other elements are combined with the $M / R$ tetrode and the hot deck to complete the functionality of the M/R system. A precision voltage divider connected between the output terminal and the zero-volt reference provides a proportional voltage feedback signal to an error amplifier. The error amplifier is located in the ground level controls system. An input voltage reference signal is compared to the output voltage feedback by the error amplifier and an error signal is generated. This signal is transmitted to the grid driver amplifier on the $M / R$ hot deck via a fiber-optic link using voltage-to-frequency conversion. The $M / R$ feedback loop is illustrated in Fig. 3.

The original MFTF grid driver amplifier design consists of a triode and tetrode tube pair connected in cascode such that the triode cathode is connected to the M/R tetrode grid and to the drive tetrode plate (through a resistance). The triode plate is biased at a positive potential $(+350 \mathrm{~V})$ with respect to the $M / R$ tetrode cathode and the drive tetrode cathode is biased to a negative potential $(-1650 \mathrm{~V})$. The amplifier was driven directly with the error signal in an open-loop configuration. With a very narrow input dynamic range and rela-

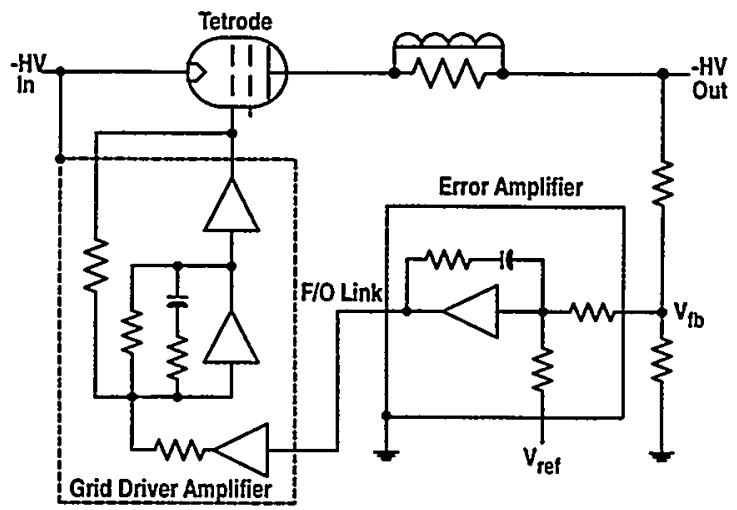

Fig. 3. A simplified schematic diagram of the $M / R$ illustrating the essential components of the feedback loop.

tively high gain, the amplifier exhibited instability, especially at frequencies above $10 \mathrm{kHz}$. The gain and phase plots are shown in Fig. 4.

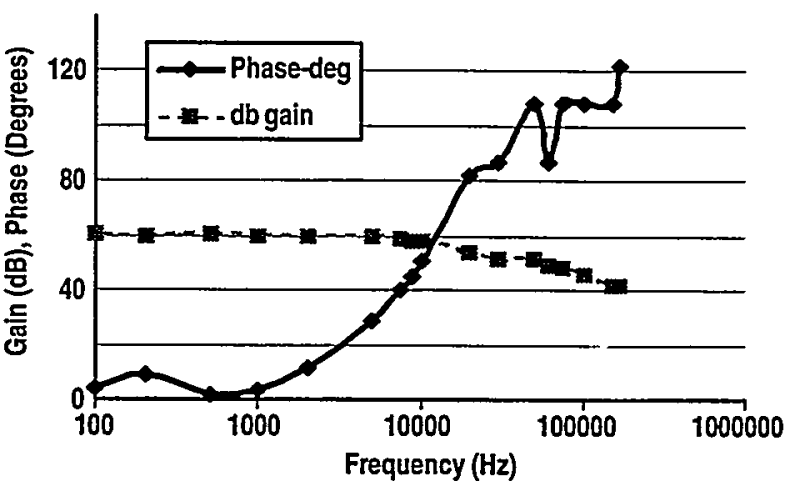

Fig. 4. The open-loop frequency response of the MFTF grid driver amplifier prior to its modification.

By creating a feedback loop within the grid driver amplifier itself, as depicted in Fig. 3, the gain of the circuit was lowered, increasing the bandwidth and improving the phase margin. Also, by increasing the input dynamic range by $20 \mathrm{~dB}$, no penalty is paid for lowering the gain and the signal to noise ratio is greatly improved. The operation of the modified circuit was observed to be much more stable and robust than previously. The frequency response of the modified circuit is plotted in Fig. 5. With the increased bandwidth, an additional pole, perhaps at $500 \mathrm{kHz}$, would further improve the phase margin and still provide sufficient operating space for the modulation requirements.

To evaluate the modulation performance and the large signal response, a $10 \mathrm{kHz}$ square wave was used to drive the amplifier. As seen in Fig. 6, the nonoptimized circuit exhibits a slightly underdamped response. The degraded risetime is a result of slew rate limit due to the lack of current drive capability of the triode. Under normal operating conditions, the grid driver would be modulated over a fraction of the dynamic range shown here. It would appear, even with no further optimization, that the modified grid driver will be able to meet the requirement of $15 \%$ amplitude square wave modulation at $20 \mathrm{kHz}$. 


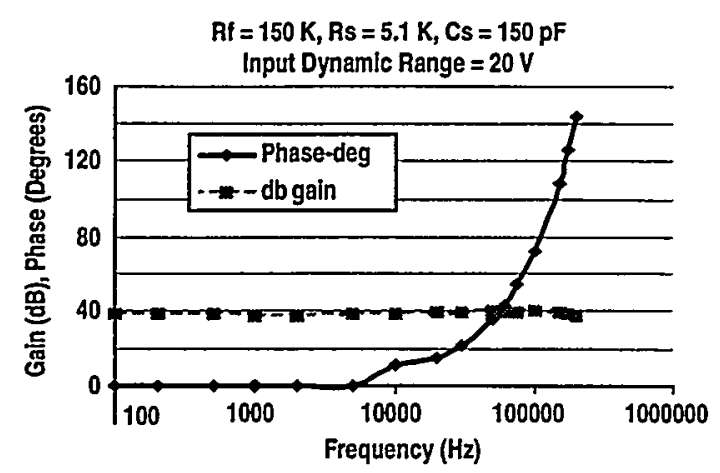

Fig. 5. The response of the grid driver amplifier modified with feedback.

\section{THE CONTROL SYSTEM}

The original MFTF control system was based on the CAMAC platform and included many custom designed circuit modules. Many of the modules, both custom and CAMAC, contained obsolete components or were simply degraded due to age (severe oxidation on contacts and solder joints). A decision was made to completely redesign the control system around a modern platform and to make the system as simple as possible.

The combination of a programmable logic controller (PLC) and state-of-the-art programmable logic devices was chosen as the new platform. A simple block diagram of the control system architecture is illustrated in Fig. 7. The PLC is a GE-FANUC 90-30 series and is used as the overall controller. It executes the operational sequences, conducts continuous interlock monitoring, and provides status indication. Another key feature of the PLC is its communications capability. The CPU364 provides ethernet, Profibus DP, and RS-232 data communications. As the ECH DIIID systems expand they will be linked, monitored, and controlled through a combination of these protocols.

The hardware interlock and the fault handler subsystems are based on high speed complex programmable logic devices (CPLD) manufactured by Xilinx. The hardware interlock serves as the master combinatorial logic of the system. All interlock, system, and fault status is processed in this subsystem. A key function of the hardware interlock is to supervise the operation of the PLC, preventing errant system operation due to a software anomaly or programming error. The fault handler processes all of the critical faults that require high speed response. It also captures and identifies the first fault in any given event. The major advantage of the

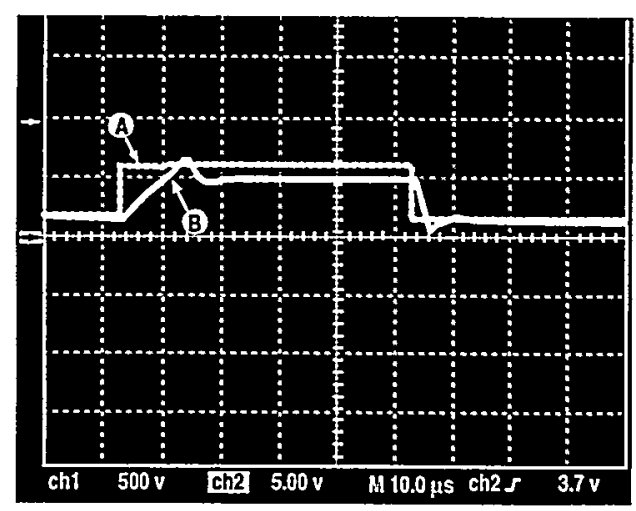

Fig. 6. The large signal response of the modified grid driver amplifier to a $10 \mathrm{kHz}$ square wave. Trace " $A$ " is the input signal (5 V/div). Trace " $B$ " is the amplifier output (500 V/div).

PLC/CPLD architecture is that the control logic and sequences are contained in software and firmware. Revisions to the system control and troubleshooting are accomplished with relative ease and speed and at very low cost.

\section{SUMMARY}

Making judicious use of the surplus MFTF hardware from LLNL, a new 8.4 MW power system for high power gyrotrons has been designed and is presently under construction at the DII-D National Fusion Facility. The testing of the crowbar switch and the grid driver amplifier indicate that these major subsystems will meet the design and performance goals of the program. The construction of the first power supply is being completed.

This is a report of work supported by the U.S. Department of Energy under contract No. DE-AC03-99ER54463. The authors wish to thank A. Nerem, D. Kellman, S. Delaware, B. Legg, J. Robinson, D. Clow, R. Davila, D. Hoyt, M. Lontoc, J. Morales, and J. Valentine for their contributions to the project.

\section{REFERENCES}

[1] W.P. Cary, et al., "The Upgrade of the DIII-D $110 \mathrm{GHz}$ $\mathrm{ECH}$ System to $6 \mathrm{MW}$," Proc. of the 18th Symp. on Fusion Engineering, Albuquerque, New Mexico (1999) to be published.

[2] C.A. Pirrie, et al., "A New Gas Discharge Switch for Discharging High Energy Capacitor Banks," Proc. of the 11 th IEEE Int. Pulsed Power Conf., Baltimore, Maryland, 1997 , p. 334.

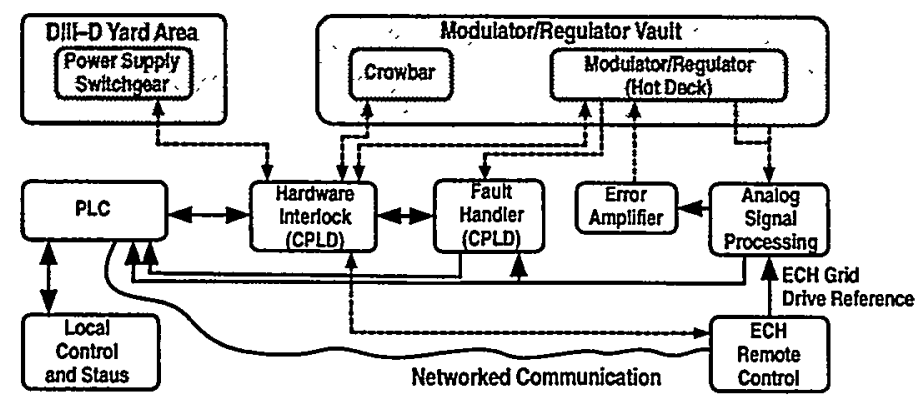

Fig. 7. The ECH power system controls architecture. The dashed lines indicate signals transmitted over fiber-optic links. 